NISTIR 8152

\title{
Report on the May 2016 ASTM E57.02 Instrument Runoff at NIST, Part 1 - Background Information and Key Findings
}

\author{
Bala Muralikrishnan \\ Prem Rachakonda \\ Meghan Shilling \\ Vincent Lee \\ Christopher Blackburn \\ Daniel Sawyer \\ Geraldine Cheok \\ Luc Cournoyer
}

This publication is available free of charge from: https://doi.org/10.6028/NIST.IR.8152

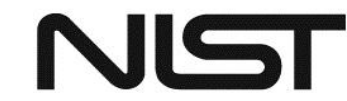

National Institute of Standards and Technology U.S. Department of Commerce 


\section{Report on the May 2016 ASTM E57.02 Instrument Runoff at NIST, Part 1 - Background Information and Key Findings}

Bala Muralikrishnan, Prem Rachakonda, Meghan Shilling, Vincent Lee, Christopher Blackburn, Daniel Sawyer Engineering Physics Division Physical Measurement Laboratory NIST

Geraldine Cheok Intelligent Systems Division Engineering Laboratory NIST

Luc Cournoyer

Measurement Science and Standards, National Research Council of Canada, Ottawa, Canada

This publication is available free of charge from: https://doi.org/10.6028/NIST.IR.8152

October 2016

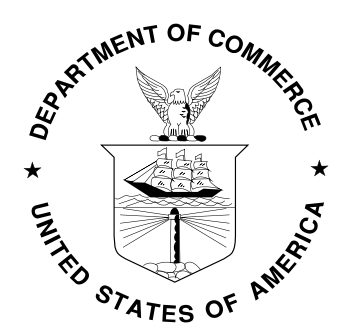

U.S. Department of Commerce Penny Pritzker, Secretary 


\section{Disclaimer}

Commercial equipment and materials may be identified in order to adequately specify certain procedures. In no case does such identification imply recommendation or endorsement by the National Institute of Standards and Technology, nor does it imply that the materials or equipment identified are necessarily the best available for the purpose. 


\section{Table of contents}

1. Introduction

2. Background information

2.1. What test positions to include in the document?

2.1.1. Why was the scope limited to spherical coordinate 3D imaging systems?

2.1.2. What was the rationale for the selection of test positions?

2.1.3. Why were 105 test lengths proposed in the early draft?

2.1.4. Why include ranging direction tests when the ASTM E2938-15 covers that?

2.1.5. Why is the test volume small?

2.2. How to realize test positions in practice?

2.2.1. Why evaluate derived-point to derived-point length?

2.2.2. Why mandate the use of sphere targets for non-ranging direction tests?

2.2.3. What target characteristics are important?

2.2.4. Are spheres suitable as targets for ranging direction test lengths?

2.3. How to process the $3 \mathrm{D}$ point cloud data?

2.3.1. How to process the sphere point cloud data?

2.3.2. How to process the plane point cloud data?

3. Key discussions and findings during and after the runoff

3.1. Overall assessment

3.1.1. Are the test procedures comprehensive while being practical?

3.1.2. Does the scope capture how a user will use the instrument?

3.2. Specific topics pertaining to the draft

3.2.1. Are two-face tests at $8 \mathrm{~m}$ sufficient to capture long range effects?

3.2.2. What artifact to use for ranging direction tests?

3.2.3. Should there be a sphere size test in the standard?

3.2.4. Should RMS values be reported?

3.2.5. Will the standard specify a minimum number of points on the sphere?

3.2.6. Will manufacturers provide a formula for the MPE?

3.2.7. Will best practices type guidelines be provided?

3.3. Observations and questions based on analysis of data collected during the runoff

3.3.1. Is a single measurement of each test position sufficient?

3.3.2. How to calculate two-face errors?

3.3.3. Is the inside test useful?

3.3.4. Is the long horizontal test useful?

3.3.5. Was sphere squishing at far distances prevalent among many systems?

3.3.6. What was the influence of data processing algorithms?

4. Conclusions

5. Acknowledgments

6. References

Appendix A List of test procedures in current draft 


\section{Introduction}

There is ongoing activity within ASTM E57.02 working group WK43218 [1] to develop a documentary standard for point-to-point distance performance evaluation of 3D imaging systems. The Dimensional Metrology Group (DMG) at the National Institute of Standards and Technology (NIST) has established facilities to realize all of the test procedures in the current draft. The DMG hosted an instrument runoff and meeting in the first week of May 2016 to allow manufacturers of 3D imaging systems to run through these test procedures. The runoff occurred between Monday 5/2/2016 and Wednesday 5/4/2016 and a meeting was held on Thursday 5/5/2016 to discuss findings. This report provides background information related to this effort and an overview of key discussions and findings during and immediately after the runoff.

The main objectives of the runoff were to determine whether the proposed test procedures would be applicable to all of the spherical coordinate 3D imaging systems that this standard will cover and to assess proposed test procedures in terms of feasibility and practicality. It was not the objective to compare instruments, hence no data is presented in this report. Participants included representatives from FARO, Leica, Trimble, Z\&F USA, Bal-tec, and API, in addition to NRC Canada and NIST staff. Basis Software provided a Surphaser unit for this effort. While Riegl USA and Nikon Metrology could not participate in May, they have expressed interest in trying out the test procedures at NIST to provide feedback.

This report, the first of two parts, is organized as follows. Section 2 provides background information related to the draft, describes some of the early issues faced by the committee, and the rationale behind the decisions made by the committee. Section 3 presents an overview of the key discussions and findings during and after the instrument runoff. Section 4 presents conclusions and describes the path forward towards completing the standard. The second part [2] of this report describes the realization of the test procedures by the DMG at NIST, uncertainties in the reference lengths, validation experiments, and supporting data.

\section{Background information}

Work on a draft standard for relative ranging performance evaluation of 3D imaging systems was nearly complete by the summer of 2013. That standard was published in 2015 as ASTM E2938-15 [3]. In the summer of 2013, a new working group (WK43218 [1]) was formed to develop a documentary standard for point-to-point performance evaluation anywhere in the work volume, not just along the ranging direction. The testing approach involves having the instrument under test (IUT) measure a calibrated length with ends A and $\mathrm{B}$ placed in different positions and orientations in the work volume (see Fig. 1). The measured errors are compared against manufacturer specified maximum permissible errors (MPEs). The instrument is considered as conforming if all errors are smaller than their corresponding MPEs.

The committee was faced with the following questions early on:

- What test positions to include in the document? 
- How to realize the test positions?

- How to process the point cloud data?

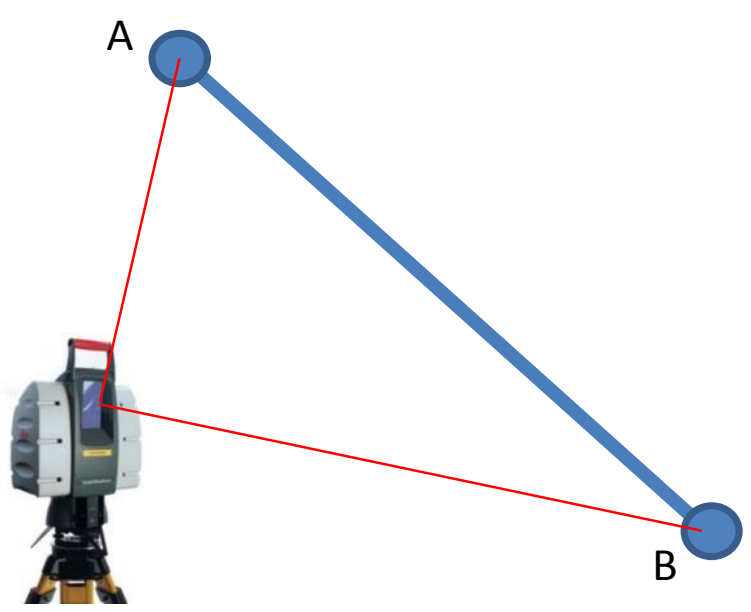

Fig. 1 A calibrated length $A B$ is measured by the IUT. If measured error is smaller than the corresponding MPE, the instrument is considered to have passed the test.

\subsection{What test positions to include in the document?}

\subsubsection{Why was the scope limited to spherical coordinate 3D imaging systems?}

The committee realized early on that error sources relevant for one class of 3D imaging systems may not be applicable to another class of 3D imaging systems. In order for the test positions to be sensitive to instrument error sources, the committee intentionally decided to narrow the scope of the standard to spherical coordinate 3D imaging systems. This was done primarily because committee members had experience developing documentary standards for other spherical coordinate 3D imaging systems such as laser trackers. Further, committee members had an understanding of error sources in spherical coordinate 3D imaging systems and could therefore recommend test positions that were sensitive to known error sources.

\subsubsection{What was the rationale for the selection of test positions?}

Spherical coordinate 3D imaging systems are similar to laser trackers in construction (see Fig. 2). The two key subsystems include a ranging unit and a two-axis gimbal to steer the laser to the target. The committee decided to adopt the ASME B89.4.19 [4] philosophy of testing the system as a whole and also to test the ranging unit independently of the overall system performance. Testing the ranging unit is important because the ranging unit provides the link to the SI unit of length and is a critical element in establishing measurement traceability. In order to determine test procedures for point-to-point distance performance, DMG staff developed detailed geometric error models $[5,6]$ of such systems and determined the influence of model parameters on measured point coordinates through simulations and experiments. Test procedures in the draft include two-face tests and point- 
to-point length tests, which are determined through a sensitivity analysis to all parameters in the geometric model [5.6].

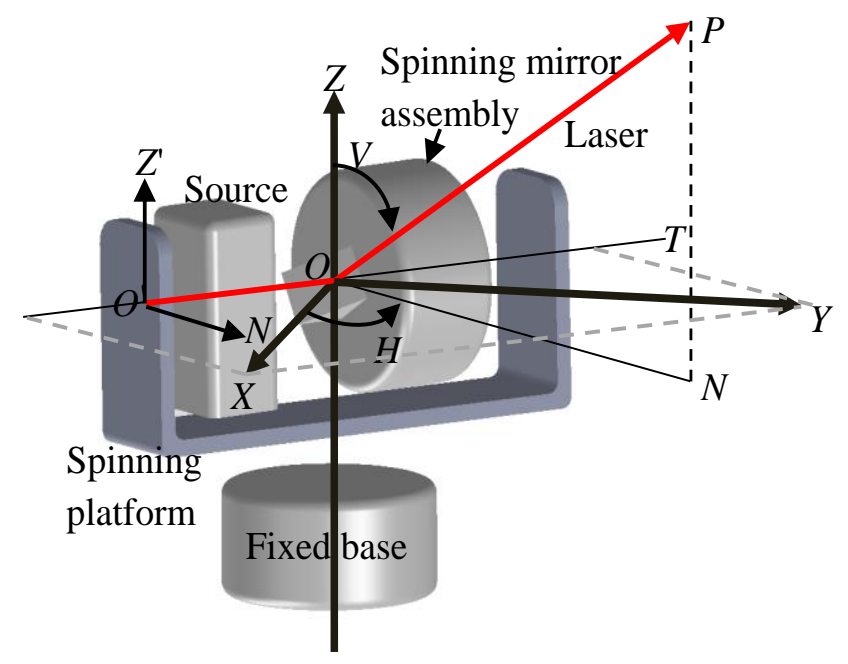

Fig. 2 Schematic of a spherical coordinate 3D imaging system.

\subsubsection{Why were 105 test lengths proposed in the early draft?}

The rationale for the selection of 105 length tests (35 test lengths, each measured 3 times) was to align the document as closely as possible to existing laser tracker standards such as the ASME B89.4.19 [4] and ISO 10360-10 [7], both of which have 105 length tests. There was discussion during and after the runoff regarding the amount of time it takes to execute 105 length tests and the consequences of that on general adoption and acceptance of the standard by the community of users and manufacturers. This issue is further discussed in section 3.1.1. Appendix A presents a list of tests in the current draft.

\subsubsection{Why include ranging direction tests when the ASTM E2938-15 covers that?}

The committee decided that including ranging direction tests within this document will make it self-contained and comprehensive. If a user intends to only use a 3D imaging system (any 3D imaging system, not simply spherical-coordinate systems) along the ranging direction, the manufacturer can specify and the user can test according to the ASTM E2938-15. If a user intends to use a spherical coordinate 3D imaging system for point-to-point length measurement anywhere in the work volume, including along the ranging direction, the manufacturer may specify and the user may test according to the procedures outlined in this draft.

\subsubsection{Why is the test volume small?}

Placing the IUT close to the calibrated artifact (used to realize the reference length) results in a larger sweep of angle between the two ends of the artifact and therefore results in higher sensitivity to some error sources. The IUT may be placed farther away if the 
reference length is long. Because it is generally not practical to realize long reference lengths, the draft recommends a shorter reference length with the IUT placed close to the artifact used to realize the length.

More generally, it should be noted that even though many of these systems can measure hundreds of meters, it is not necessary to create a long reference length to test the volumetric performance of these instruments. While the ranging performance may be evaluated along a radial direction over long lengths, errors associated with the angular axes may be evaluated using strategically placed lengths closer to the IUT while still achieving sensitivity to error sources associated with the angular axes.

\subsection{How to realize the test positions in practice?}

\subsubsection{Why evaluate derived-point to derived-point length?}

Most 3D imaging systems cannot measure a single point and can only scan a region and produce a point cloud. This brings up two issues: the fact that the points are inherently noisy and the question of which point in the point cloud to use. In order to reduce the influence of noise while capturing systematic error sources from within the instrument and to address which point to use, point clouds obtained from targets at the ends of the reference length are reduced to a single derived point. The standard therefore requires the evaluation of the performance of derived-point to derived-point distance measurements by spherical coordinate 3D imaging systems. Any subsequent use of the term point-to-point length in this report implies derived-point to derived-point length. The targets at the two ends of the artifact used to create the reference length are identical (for example, spheres of nominally the same size, form, reflectance).

\subsubsection{Why mandate the use of sphere targets for non-ranging direction tests?}

The decision to consider derived-point to derived-point length implied the use of targets at the ends of the length. This introduced a key question into the discussion - i.e., will a user be free to choose any target to realize the reference length? The committee decided that allowing users to choose their own targets will result in manufacturers publishing specifications that cannot be compared. The committee considered different targets that could potentially be used such as spheres, contrast targets, and trihedral targets. 

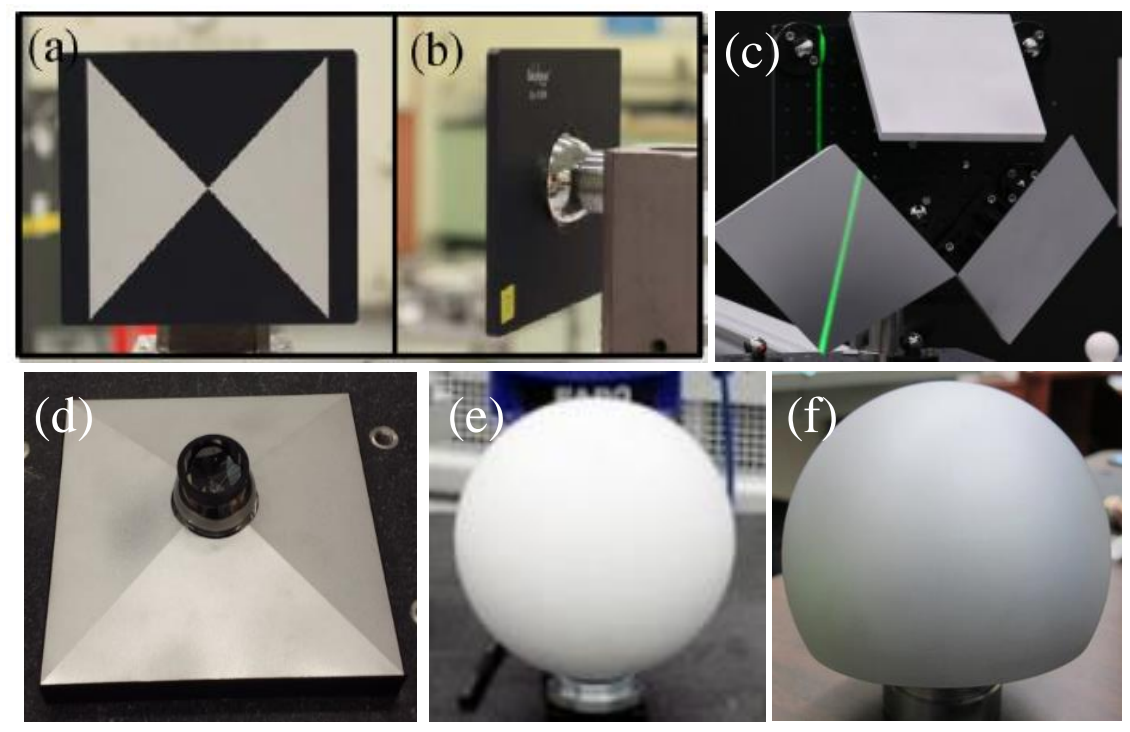

Fig. 3 (a) Front view of a contrast target, (b) back view of a contrast target showing the partial sphere, (c) a trihedral target [8], (d) a tetrahedral target [9], (e) commercial white painted plastic scanning sphere, and $(f)$ commercial aluminum satin finish sphere target with $38.1 \mathrm{~mm}$ (1.5 in) SMR nest centrally located

Contrast targets were not chosen because the derived point is determined using intensity images and therefore are not dimensional measurements whereas the scope of the standard is to assess the dimensional measurement performance. Further, such derived points are determined using proprietary algorithms that a user may not have access to.

Trihedral targets or tetrahedral targets were determined to be feasible but there are no commercially available targets that can be readily purchased. Further, determining the reference distance using a trihedral or tetrahedral target can be challenging.

A sphere, on the other hand, provides a unique derived point that can be determined easily using commercially available software tools. Further, there are commercially available sphere targets that have a $38.1 \mathrm{~mm}$ (1.5 in) spherically mounted retroreflector (SMR) nest centrally located that allows a user to easily establish the reference distance using a laser tracker. The committee therefore decided that the standard will mandate the use of sphere targets for all two-face tests and non-ranging direction point-to-point length tests. Targets for ranging direction tests are addressed in section 2.2.4.

\subsubsection{What target characteristics are important?}

The committee decided that the standard will provide acceptable ranges of values for the properties of the sphere target such as size, form, reflectance and diffusivity factors; any sphere that has characteristics that meets these ranges of values may be used as targets for testing. 
In order to determine suitable targets for initial trials, committee members studied different sphere targets to identify those that are friendly to the 3D imaging systems. Repeatability measurements were performed on numerous sphere materials (aluminum, steel, titanium, plastic), color/texture (media-blasted, shiny, painted white), and sizes (diameters from 75 $\mathrm{mm}$ to $400 \mathrm{~mm}$ ). It was determined that white spheres and dull gray, media-blasted spheres provide repeatable centers.

In addition to obtaining repeatable centers with the 3D imaging system, it is important that the center determined by the 3D imaging system be coincident with the center determined by the reference instrument such as a laser tracker. For this purpose, it is important that the form error of the sphere be as small as possible. Contact probe CMM measurements on a commercial white plastic (shown in Fig. 4) indicate form error on the order of $0.3 \mathrm{~mm}$. This form error is systematic and not random, as seen in Fig. 4; this implies that the center determined by the 3D imaging system and the tracker (if the SMR is manually probed on the surface) may be different depending on the region of the sphere under measurement. It is possible to obtain metallic spheres with lambertian/matte finish with form error under $10 \mu \mathrm{m}$; these may be preferable as targets for performance testing of 3D imaging systems.

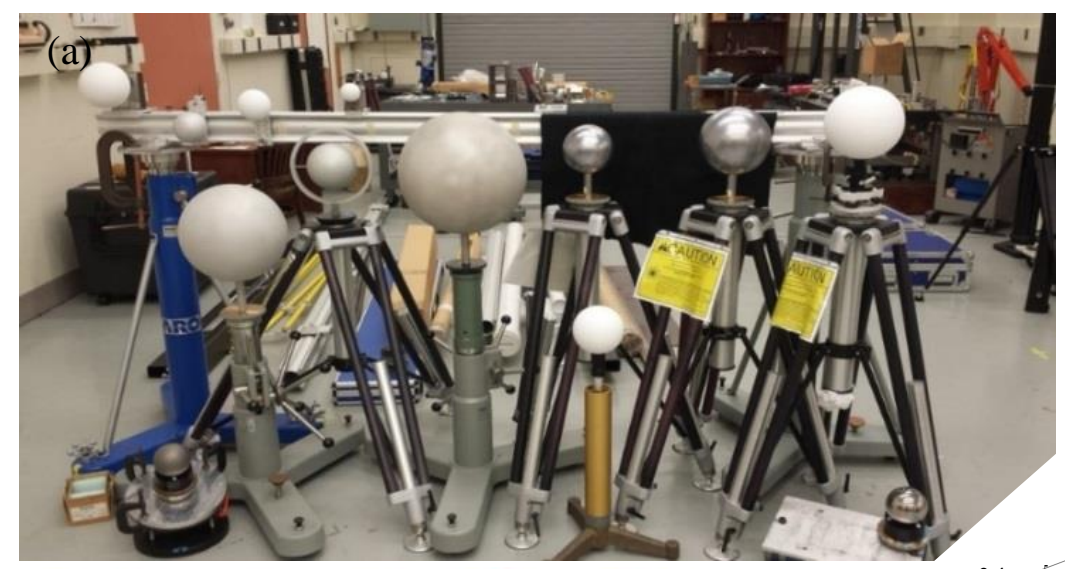

(c)
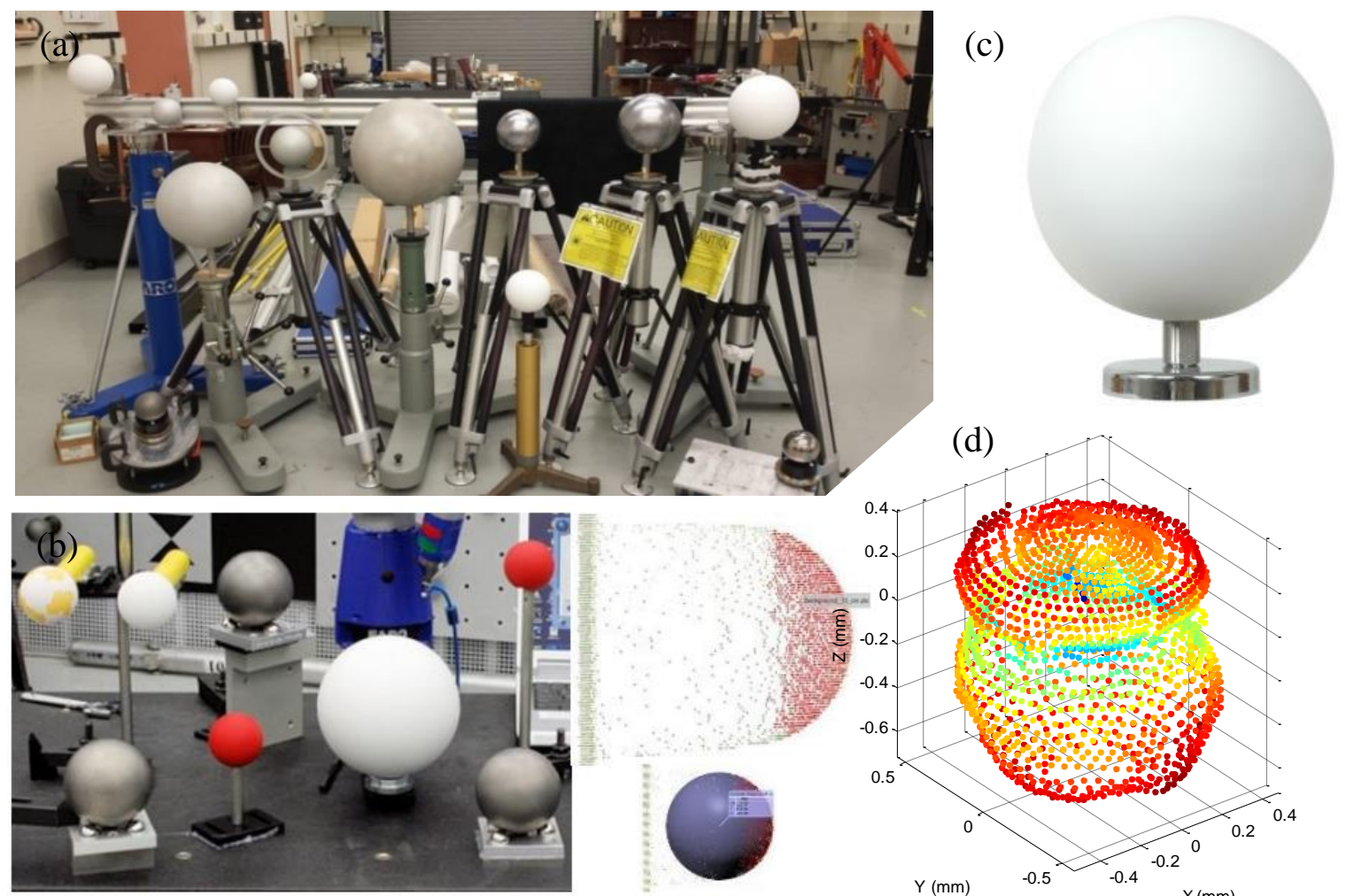

(d)

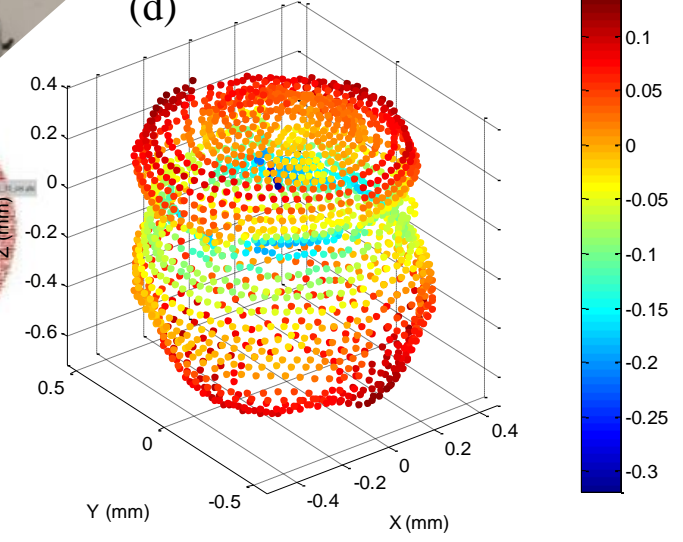

Fig. 4 (a) Variety of sphere targets tested at NIST [5], (b) sphere targets tested at the National Research Council (NRC) of Canada [10], (c) a commercial white painted plastic sphere, and (d) form of that sphere as measured using a contact probe CMM 


\subsubsection{Are spheres suitable as targets for ranging direction test lengths?}

Sphere targets were scanned at different distances from the 3D imaging system in the tapetunnel facility of the DMG. These experiments indicated that the sphere may appear to the scanner to be increasingly smaller (squished) at farther distances with some 3D imaging systems. When a least-squares, constrained radius sphere is fit to such data, the center of the constrained-fit sphere moves farther away from the scanner along the radial direction resulting in an apparent ranging error (see Fig. 5). This error can sometimes be fairly large, at times, masking the ranging error of the 3D imaging system itself. For example, data from one 3D imaging system showed the unconstrained radius of a nominal $100 \mathrm{~mm}$ sphere decreased by as much as $10 \mathrm{~mm}$. This squishing resulted in an apparent ranging error of about $2 \mathrm{~mm}$ when the center was determined using a constrained least-squares method.

(a)

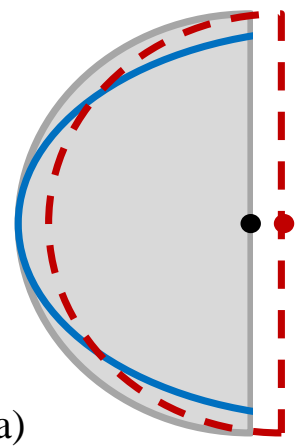

Near position

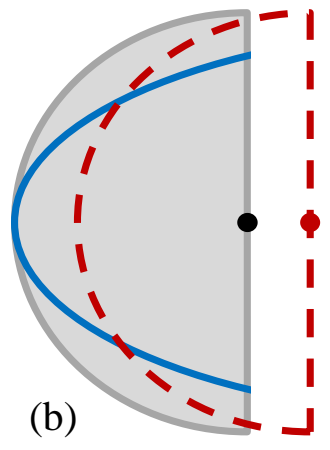

Far position
Grey $=$ actual sphere

Solid blue line $=3 \mathrm{D}$ imaging system

data

Dashed red line $=$ best fit sphere

Fig. 5 The effect of sphere squishing on range error, (a) at the near position, the squishing effect is small as shown by the solid blue line and therefore the least-squares best-fit sphere produces a center that is somewhat displaced from the true center, $(b)$ at the far position, the squishing effect is large and therefore the least-squares best-fit sphere produces a center that is displaced from the true center by a large amount. The increasing squishing of the sphere therefore results in an apparent ranging error.

Given this sphere squishing problem and the resulting error in range, it was decided to perform the ranging portion of the runoff with a plane artifact and again separately with a sphere artifact. One of the objectives of the runoff was to determine if multiple systems displayed the sphere-squishing problem and accordingly decide how to address this problem. Fig. 6(a) shows the plate-sphere artifact used during the runoff. The sphere simply serves as a fiducial to identify the point on the plane that is closest to the SMR center. The SMR itself is located centrally inside the sphere and is measured from the back. Fig. 6(b) shows the bare-sphere artifact. In this case, the sphere center determined by the 3D imaging system is itself used in the ranging distance calculation.

Another issue with the use of spheres for the ranging portion of the test was the ability to obtain a sufficient number of points on the sphere at the longer distances. It may be necessary to use larger spheres which increase the cost of conducting this test. 


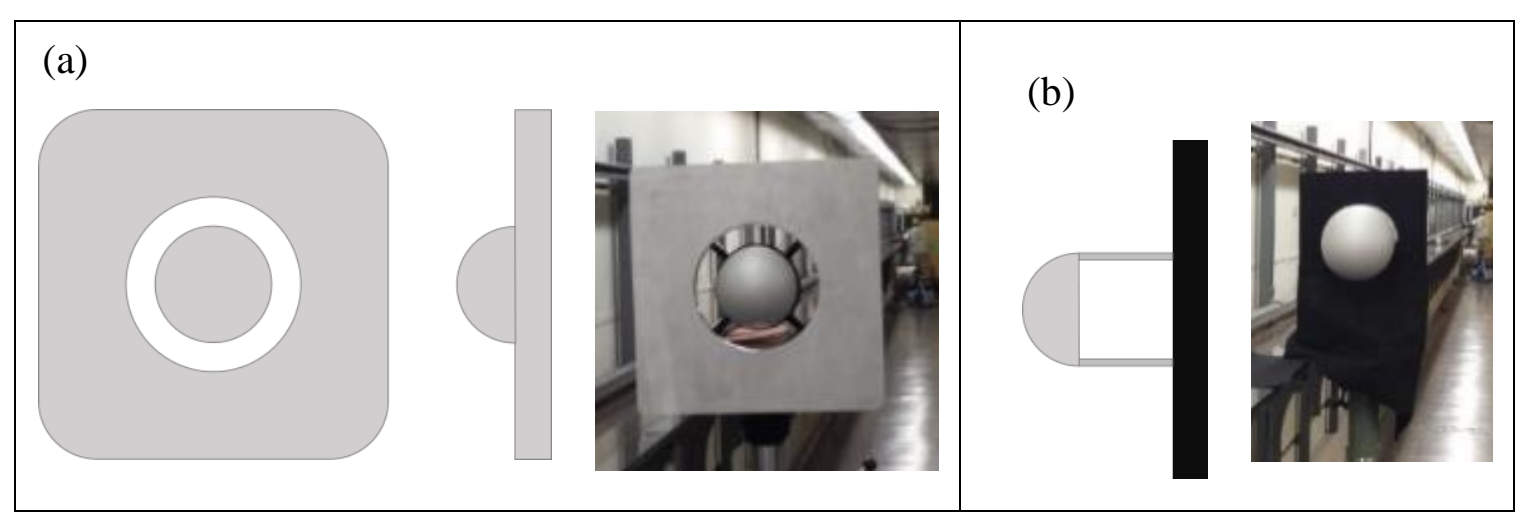

Fig. 6 Ranging artifacts used during the runoff

(a) a plate-sphere artifact, (b) a bare-sphere artifact

\subsection{How to process the 3D point cloud data?}

The committee realized that different segmentation and filtering algorithms can produce different center-to-center distances even when applied on the same 3D point cloud data. Because it is not within the scope of the standard to test the effectiveness of the algorithm itself, it was decided that the standard would include a common method of processing the data. A key objective of this instrument runoff was to acquire data from as many systems as possible to determine the appropriate data processing algorithm that will then be described in the standard.

\subsubsection{How to process the sphere point cloud data?}

The process of reducing raw data to a sphere center involves an initial segmentation of the sphere data from the raw point cloud, a determination of an initial sphere center, the final segmentation, followed by the final center determination. The committee has not yet determined if the initial segmentation will be performed manually or algorithmically. Once an initial center has been determined with the instrument acquisition software, the draft standard currently describes a final segmentation based on a $\pm 60^{\circ}$ cone angle (that is, a $60^{\circ}$ half apex angle, making a $120^{\circ}$ full apex angle - see Fig. 7). The apex of the cone is coincident with the initial center of the sphere. The center line of this cone is coaxial with the line that runs from the center of the sphere to the origin of the IUT. This rule may be revised based on findings from the analysis of all data acquired during the runoff. 


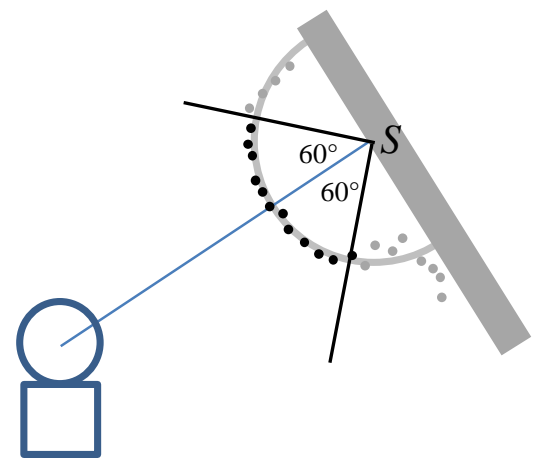

Fig. 7 Cone angle based segmentation with $a \pm 60^{\circ}$ angle

\subsubsection{How to process the plane point cloud data?}

A method to process point cloud data from a plane is currently described in the ASTM E2938-15. This committee has yet to determine if it will simply adopt the language in that standard or describe alternate methods to segment and process plane data.

\section{Key discussions and findings during and after the runoff}

Several discussions were held during the runoff and the main meeting (of the ASTM E57.02 working group WK43218) on 5/5/2016, and in subsequent online teleconference meetings. Below is a summary of key discussions and findings.

\subsection{Overall assessment}

\subsubsection{Are the test procedures comprehensive while being practical?}

Several manufacturers noted that while the standard has to be comprehensive, i.e., detect all known error sources, it also has to be practical, i.e., the test procedures should be easily realizable and executable in a reasonable period of time. Executing the test procedures during the runoff required many hours (almost a full day) and multiple setups. While automating the process will help reduce the amount of time required, committee members believe that addressing this concern is critical to the widespread adoption of the standard. Members will therefore attempt to reduce the number of test procedures without diluting the rigor of the standard. This can be achieved by performing one measurement instead of three measurements required for every position and not adhering to the ISO convention of 105 test measurements.

\subsubsection{Does the scope capture how a user will use the instrument?}

Some manufacturers commented that the test procedures in the current draft do not reflect how a user will use the instrument. The draft describes using idealized sphere targets and the errors obtained from these test procedures may not be reflective of the errors seen when 
measuring real world objects. Many users may also use intensity data for target localization but the test procedures in the draft do not address that, and only use geometrical targets.

Committee members pointed out that the scope of this standard has been intentionally narrowed to how the instrument performs for ideal targets (such as used during registration) so as to make the task of creating the standard more manageable. Future standards will be needed to address the implications of target properties such as reflectance factor, texture, form, and angle of incidence on measurement errors.

\subsection{Specific topics pertaining to the draft}

\subsubsection{Are two-face errors at $8 \mathrm{~m}$ sufficient to capture long range effects?}

Manufacturers of some systems that can measure beyond $100 \mathrm{~m}$ indicated that the target at the far position of $8 \mathrm{~m}$ is not sufficiently far away to capture all angular errors. They indicated that internal procedures they use involve performing two-face tests at a near distance of around $10 \mathrm{~m}$ and a far distance of beyond $30 \mathrm{~m}$. In order to perform the test at steep elevation angles (elevation angles beyond $\pm 45^{\circ}$ ) and far distances, one of the manufacturers use a mirror as shown in Fig. 8. In Fig. 8, two-face tests are performed using a single target, but the use of the mirrors allow the test to be performed as if the target was at three different elevation angles, one greater than $+45^{\circ}$, one at about $0^{\circ}$, and one less than $-45^{\circ}$. The committee decided to consider these comments when revising the test positions.

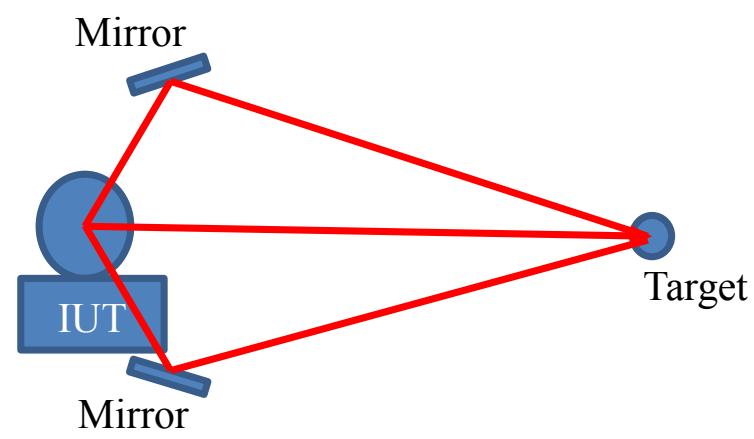

Fig. 8 Use of mirrors to achieve steep elevation angles when performing two-face tests at far locations. Side view of set-up.

\subsubsection{What artifact to use for ranging direction tests?}

There was consensus that planar targets be used for the ranging direction tests. There was also consensus that the standard should not specify how the plane will be realized in practice (i.e., a plate carefully aligned normal to the ranging axis, a plate-sphere artifact, etc.). Users should be allowed to realize it per the ASTM E2938-15 or through other means such the plate-sphere artifact.

There was discussion that while the plate-sphere artifact allows users to perform ranging measurements on a planar geometry without the need to carefully align the plate, the sphere 
does occupy a substantial portion of the center of the plate (see Fig. 6). Some participants questioned whether the plate-sphere artifact allows for a true ranging measurement because the data from the center of the plate is unavailable because of the sphere. At near positions, the data from the plate used to determine the best-fit plane will span a large angular range and therefore the measurement incorporates angular errors. NIST staff members who were primarily involved in the design of the artifact concurred; they will attempt to re-design the artifact so that a true ranging direction measurement can be performed without the need to carefully align the plate with respect to the radial direction.

\subsubsection{Should there be a sphere size test in the standard?}

The committee did recognize that performing relative range tests with planar targets effectively masked a potentially important error source in some systems, i.e., the inability to correctly measure size of spheres at far distances. There was some discussion as to whether a test to determine if an IUT can determine the size of a sphere be included in the draft, but it was pointed out that the apparent squishing of spheres is due to the specific geometry of the target, possible multi-path reflection, and nature of the measurement technology (pulse vs time of flight). Because the scope of this standard is not to test for target-induced errors, it was decided to include this information (sphere squishing) as a non-mandatory appendix so users are aware of the problem.

\subsubsection{Should RMS values be reported?}

Manufacturers of most systems currently provide root mean square (RMS) noise values as part of their specifications. However, these values are not currently tied to specific acquisition rates and are based off of different artifacts (and associated properties such as reflectance factor). There was consensus that the RMS values based on a flat plane be reported along with the acquisition rate. It was noted that the ASTM E2938-15 does require RMS values to be noted as part of that test. No decision has been made on whether to report RMS values from sphere point-cloud data.

\subsubsection{Will the standard specify a minimum number of points on the sphere?}

It was decided that the standard will specify a minimum number of points that have to be collected on the spheres. It is not clear yet as to what that minimum value should be; some manufacturers indicated that 300 points on a sphere should be more than sufficient to obtain a reliable center. During the runoff, manufactures were asked to select their point density settings based on acquiring at least 1000 points on each sphere. In addition to guidance on point density settings, the standard will also require that no special software filtering of the data (other than what is routinely done on all data sets acquired by the system) be performed.

\subsubsection{Will manufacturers provide a formula for the MPE?}

It is anticipated that each manufacturer will provide a formula so that users can calculate the MPE (from range and angle) not only for the tests described in the standard, but for any 
derived-point to derived-point length. The committee discussed, but did not decide, on whether the standard will provide a general form of a formula to calculate the MPE for any point-to-point length in a manner similar to the ISO 10360-10.

\subsubsection{Will best practices type guidelines be provided?}

During the runoff, it was noted that some manufacturers were operating the instrument using the touch-pad on the instrument; such handling could potentially displace the instrument coordinate system. This could be a problem if length calculation involves information from more than one scan, such as a two-face test or a relative range test.

Some manufacturers turned the instrument off between scans to replace the battery. The committee believes that some best practices type guidance should be provided in the document on how to perform the tests.

\subsection{Observations and questions based on analysis of data collected during the runoff}

\subsubsection{Is a single measurement of each test position sufficient?}

Processing of the data from all systems available during the runoff revealed that the one standard deviation repeatability was generally much smaller than the observed errors. While the MPEs for the tests are not available at this time, analysis of the data does suggest that a single measurement of each test position may be sufficient, thus significantly reducing the time and effort needed to execute the tests.

The draft currently has a non-mandatory appendix that describes a repeatability test which can be performed prior to the mandatory tests. This will allow the user to determine if there are any issues related to the rigidity of the setup that will affect measurements.

\subsubsection{How to calculate two-face errors?}

Two-face errors may be calculated as the Euclidean distance between the center of the sphere target determined from a front-face scan and the center determined from a backface scan. However, such calculation also includes the component along the ranging direction. The primary purpose of two-face testing is to calculate the magnitude of angular errors and therefore there is ongoing discussion as to whether two-face errors have to be calculated along the angular axes only. The data processed after the runoff indicated that ranging direction components are generally small in comparison to the angular components, thus Euclidean distance between the front-face and back-face centers may produce practically the same two-face error as that obtained by ignoring the ranging direction component. 


\subsubsection{Is the inside test useful?}

For several systems tested, the inside test (the IUT is placed in-line and in-between two targets, the distance between the targets being previously calibrated) produced the largest error of all the tests performed during the runoff. The inside test captures the constant error in range; a large error in this test implies that the $3 \mathrm{D}$ imaging system is reading consistently longer or shorter. This in turn affects every measurement performed by the 3D imaging system. This term cannot be captured in a two-face test and therefore it is important that this test be performed.

The inside test may be performed by scanning each sphere in front-face only or by scanning one sphere in front-face while simultaneously scanning the other sphere in the back-face. Each of these methods is sensitive to different set of parameters. The committee has not made a decision yet on which approach to use. During the runoff, some of manufacturers performed the test both ways.

\subsubsection{Is the long horizontal test useful?}

The long horizontal test captures even-order scale errors in the horizontal angle encoder that cannot be captured by two-face tests. For most 3D imaging systems, the errors from this test were of the same order of magnitude as from other point-to-point length tests, especially the symmetrical horizontal length test at the near position. For one system however, this test produced the largest error.

All of the two-face tests and most point-to-point length tests can be realized using a single scale bar with three spheres (one of which is centrally mounted). The long horizontal test requires two targets placed about $6 \mathrm{~m}$ to $8 \mathrm{~m}$ apart, and is therefore an additional burden to the users. There was debate as to whether this test should be included in the main document as a mandatory test, listed as a default option for one of the two user defined tests, or simply moved to a non-mandatory appendix that would inform the user of the value of this test. The committee has not decided on how to proceed on this issue.

\subsubsection{Was sphere squishing at far distances prevalent on many systems?}

Relative range tests during the runoff were performed with two different artifacts - a platesphere artifact and a bare-sphere artifact. Data from more than one system showed the unconstrained radius of the spheres decreased at far distances while for one system, the radius actually increased somewhat.

\subsubsection{What was the influence of data processing algorithms?}

In order to provide results to the manufacturers after the runoff, data were processed by segmenting based on a $\pm 60^{\circ}$ cone angle method. It was noticed that different implementations of the cone angle method yielded point-to-point lengths that differed by up to $0.05 \mathrm{~mm}$, largely because of the initial centers varied considerably from method to 
method. If outliers or artifacts were present in the data, differences on the order of $0.1 \mathrm{~mm}$ were observed. It is clear that the standard has to provide a uniform algorithm that can be applied to all data. The committee will make a recommendation after studying the data more carefully.

\section{Conclusions}

The main objectives of the runoff were to determine whether the proposed test procedures would be applicable to all of the spherical coordinate 3D imaging systems that this standard will cover and to assess proposed tests procedures in terms of feasibility and practicality. None of the manufacturers that participated in the runoff had any problems performing the proposed test procedures in the draft.

A key finding that emerged from the runoff was that in order for the standard to be widely adopted, the test procedures should not only be comprehensive (capable of detecting errors), they should also be practical (in terms of the time and effort involved in realizing them). The committee is currently revising the test procedures to address this concern.

Another objective of the runoff was to acquire data from as many systems as possible so that the committee may then determine a set of data processing algorithms that are applicable to all systems. The committee is currently studying all of the data acquired; a recommendation will be made shortly.

\section{Acknowledgements}

The authors thank all participants of the instrument runoff and the biweekly E57 meetings for supporting this standards effort, Dr. Kam Saidi and Dr. Steve Phillips for helpful discussions, and Dr. Craig Shakarji and Dr. Marek Franaszek for carefully reviewing this document.

\section{References}

1. WK43218. ASTM E57.02, New test methods for evaluating the performance of medium-range, spherical coordinate, 3D imaging systems for point-to-point distance measurements

2. NISTIR 8153, Report on the May 2016 ASTM E57.02 instrument runoff at NIST, Part 2 - NIST realization of test procedures and uncertainties in the reference lengths, 2016

3. ASTM E2938-15, Standard test method for evaluating the relative-range measurement performance of $3 \mathrm{D}$ imaging systems in the medium range

4. ASME B89.4.19-2006 Standard - Performance Evaluation of Laser-Based Spherical Coordinate Measurement Systems, www.asme.org

5. Bala Muralikrishnan, Meghan Shilling, Prem Rachakonda, Wei Ren, Vincent Lee, and Daniel Sawyer, Toward the development of a documentary standard for derived-point to derived-point distance performance evaluation of spherical coordinate 3D imaging systems, Journal of Manufacturing Systems, 37 (2), p. 550-557, 2015 
6. B. Muralikrishnan, M. Ferrucci, D. Sawyer, G. Gerner, V. Lee, C. Blackburn, S. Phillips, P. Petrov, Y. Yakovlev, A. Astrelin, S. Milligan, and J. Palmateer, Volumetric performance evaluation of a laser scanner based on geometric error model, Precision Engineering, 40, p. 139-150, 2015

7. ISO 10360-10:2016. Acceptance and reverification tests for coordinate measuring systems (CMS) -- Part 10: Laser trackers for measuring point-to-point distances

8. David MacKinnon, Luc Cournoyer, and J.-Angelo Beraldin, Single-plane versus threeplane methods for relative range error evaluation of medium-range 3D imaging systems, Proceedings of the SPIE, vol. 9528, 2015

9. P. Rachakonda, B. Muralikrishnan, M. Shilling, G. Cheok, V. Lee, C. Blackburn, D. Everett, D. Sawyer, Targets for relative range error measurement of 3D imaging systems, Proceedings of the CMSC 2016

10. J.-Angelo Beraldin, David MacKinnon, and Luc Cournoyer, Metrological characterization of 3D imaging systems: Progress report on standards development, $17^{\text {th }}$ International Congress of Metrology, Paris, France, 2015 


\section{Appendix A List of test procedures in current draft}

The draft currently has 12 two-face tests, each performed three times, for a total of 36 twoface tests. These are listed in Table A1, a schematic is shown in Fig. A1. The draft also has 35 point-to-point length tests, each performed three times, for a total of 105 length tests (Fig. A2 and A3). The point-to-point length tests include the near symmetric positions (Table A2), the near asymmetric positions (Table A3), the far symmetric positions (Table A4), the ranging direction positions (which include the inside test and the relative range tests) (Table A5), and the user-defined positions (Table A6). All of the tests listed in this Appendix were performed during the runoff. Two relative range positions in addition to the three required positions in Table A5 were performed; these were considered as the user defined positions.

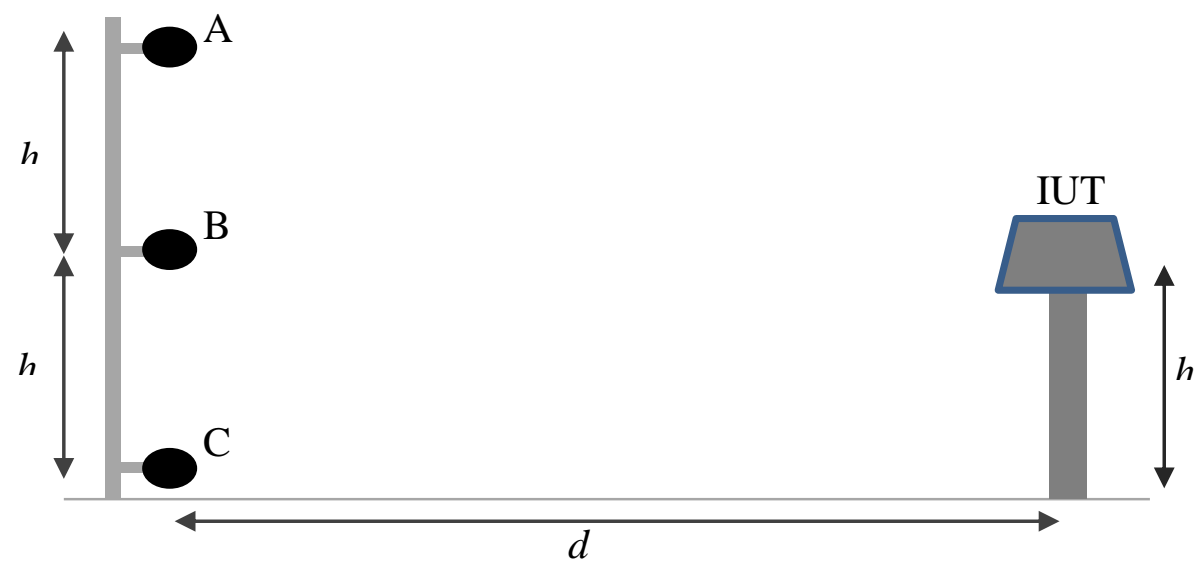

Fig. A1 Schematic of two-face test setup 
Table A1 List of two-face test positions (see Fig. A1)

\begin{tabular}{|c|c|c|c|c|}
\hline $\begin{array}{l}\text { Position } \\
\text { number }\end{array}$ & $\begin{array}{l}\text { Distance } \\
\text { from IUT, } d \\
\text { (meters) }\end{array}$ & $\begin{array}{l}\text { Height of the } \\
\text { sphere relative to } \\
\text { the IUT, } h \text { (meters) }\end{array}$ & $\begin{array}{l}\text { Azimuth } \\
\text { angle } \\
\text { (degrees) }\end{array}$ & Description \\
\hline 1 & $\begin{array}{l}\text { As close as } \\
\text { possible, } \\
\text { less than } 3 \mathrm{~m}\end{array}$ & $\begin{array}{c}1.5 \mathrm{~m} \text { to } 3 \mathrm{~m} \text { above } \\
\text { IUT }\end{array}$ & $0^{\circ}$ & $\begin{array}{l}\text { Measurements on sphere A with the IUT at } \\
\text { the near position and nominally at } 0^{\circ} \\
\text { azimuth angle. }\end{array}$ \\
\hline 2 & $\begin{array}{l}\text { As close as } \\
\text { possible, less } \\
\text { than } 3 \mathrm{~m}\end{array}$ & Same height as IUT & $0^{\circ}$ & $\begin{array}{l}\text { Measurements on sphere B with the IUT at } \\
\text { the near position and nominally at } 0^{\circ} \\
\text { azimuth angle. }\end{array}$ \\
\hline 3 & $\begin{array}{l}\text { As close as } \\
\text { possible, less } \\
\text { than } 3 \mathrm{~m}\end{array}$ & $\begin{array}{c}1.5 \mathrm{~m} \text { to } 3 \mathrm{~m} \text { below } \\
\text { IUT }\end{array}$ & $0^{\circ}$ & $\begin{array}{l}\text { Measurements on sphere } \mathrm{C} \text { with the IUT at } \\
\text { the near position and nominally at } 0^{\circ} \\
\text { azimuth angle. }\end{array}$ \\
\hline 4 & $\begin{array}{l}\text { As close as } \\
\text { possible, less } \\
\text { than } 3 \mathrm{~m}\end{array}$ & $\begin{array}{c}1.5 \mathrm{~m} \text { to } 3 \mathrm{~m} \text { above } \\
\text { IUT }\end{array}$ & $90^{\circ}$ & $\begin{array}{l}\text { Measurements on sphere A with the IUT at } \\
\text { the near position and nominally at } 90^{\circ} \\
\text { azimuth angle. }\end{array}$ \\
\hline 5 & $\begin{array}{l}\text { As close as } \\
\text { possible, less } \\
\text { than } 3 \mathrm{~m}\end{array}$ & Same height as IUT & $90^{\circ}$ & $\begin{array}{l}\text { Measurements on sphere B with the IUT at } \\
\text { the near position and nominally at } 90^{\circ} \\
\text { azimuth angle. }\end{array}$ \\
\hline 6 & $\begin{array}{l}\text { As close as } \\
\text { possible, less } \\
\text { than } 3 \mathrm{~m}\end{array}$ & $\begin{array}{c}1.5 \mathrm{~m} \text { to } 3 \mathrm{~m} \text { below } \\
\text { IUT }\end{array}$ & $90^{\circ}$ & $\begin{array}{l}\text { Measurements on sphere } \mathrm{C} \text { with the IUT at } \\
\text { the near position and nominally at } 90^{\circ} \\
\text { azimuth angle. }\end{array}$ \\
\hline 7 & $6 \mathrm{~m}$ to $8 \mathrm{~m}$ & $\begin{array}{c}1.5 \mathrm{~m} \text { to } 3 \mathrm{~m} \text { above } \\
\text { IUT }\end{array}$ & $0^{\circ}$ & $\begin{array}{l}\text { Measurements on sphere A with the IUT at } \\
\text { the far position and nominally at } 0^{\circ} \text { azimuth } \\
\text { angle. }\end{array}$ \\
\hline 8 & $6 \mathrm{~m}$ to $8 \mathrm{~m}$ & Same height as IUT & $0^{\circ}$ & $\begin{array}{l}\text { Measurements on sphere B with the IUT at } \\
\text { the far position and nominally at } 0^{\circ} \text { azimuth } \\
\text { angle. }\end{array}$ \\
\hline 9 & $6 \mathrm{~m}$ to $8 \mathrm{~m}$ & $\begin{array}{c}1.5 \mathrm{~m} \text { to } 3 \mathrm{~m} \text { below } \\
\text { IUT }\end{array}$ & $0^{\circ}$ & $\begin{array}{l}\text { Measurements on sphere } \mathrm{C} \text { with the IUT at } \\
\text { the far position and nominally at } 0^{\circ} \text { azimuth } \\
\text { angle. }\end{array}$ \\
\hline 10 & $6 \mathrm{~m}$ to $8 \mathrm{~m}$ & $\begin{array}{c}1.5 \mathrm{~m} \text { to } 3 \mathrm{~m} \text { above } \\
\text { IUT }\end{array}$ & $90^{\circ}$ & $\begin{array}{l}\text { Measurements on sphere A with the IUT at } \\
\text { the far position and nominally at } 90^{\circ} \\
\text { azimuth angle. }\end{array}$ \\
\hline 11 & $6 \mathrm{~m}$ to $8 \mathrm{~m}$ & Same height as IUT & $90^{\circ}$ & $\begin{array}{l}\text { Measurements on sphere B with the IUT at } \\
\text { the far position and nominally at } 90^{\circ} \\
\text { azimuth angle. }\end{array}$ \\
\hline 12 & $6 \mathrm{~m}$ to $8 \mathrm{~m}$ & $\begin{array}{c}1.5 \mathrm{~m} \text { to } 3 \mathrm{~m} \text { below } \\
\text { IUT }\end{array}$ & $90^{\circ}$ & $\begin{array}{l}\text { Measurements on sphere } \mathrm{C} \text { with the IUT at } \\
\text { the far position and nominally at } 90^{\circ} \\
\text { azimuth angle. }\end{array}$ \\
\hline
\end{tabular}


Table A2 Near symmetric test positions (see Fig A2), reference length $A B$ is $3 \mathrm{~m}$ to $6 \mathrm{~m}$ long

\begin{tabular}{|c|c|c|c|c|}
\hline $\begin{array}{l}\text { Position } \\
\text { number }\end{array}$ & $\begin{array}{l}\text { Distance } d \\
\text { from IUT } \\
\text { (meters) }\end{array}$ & $\begin{array}{l}\text { Azimuth } \\
\text { angle } \\
\text { (degrees) }\end{array}$ & Description & $\begin{array}{l}\text { Sub- } \\
\text { figure }\end{array}$ \\
\hline 1 & $\begin{array}{l}\text { As close as } \\
\text { possible, } \\
\text { less than } 3 \mathrm{~m}\end{array}$ & $0^{\circ}$ & $\begin{array}{l}\text { Horizontal length } \mathrm{AB} \text { is placed at the same height as the } \\
\text { IUT, with the IUT nominally at } 0^{\circ} \text { azimuth angle when } \\
\text { facing the center of the line } \mathrm{AB} \text {. }\end{array}$ & $\mathrm{a}$ \\
\hline 2 & $\begin{array}{l}\text { As close as } \\
\text { possible, less } \\
\text { than } 3 \mathrm{~m}\end{array}$ & $90^{\circ}$ & $\begin{array}{l}\text { Horizontal length AB is placed at the same height as the } \\
\text { IUT, with the IUT nominally at } 90^{\circ} \text { azimuth angle when } \\
\text { facing the center of the line. }\end{array}$ & $\mathrm{a}$ \\
\hline 3 & $\begin{array}{l}\text { As close as } \\
\text { possible, less } \\
\text { than } 3 \mathrm{~m}\end{array}$ & $0^{\circ}$ & $\begin{array}{l}\text { The center of the vertical length } \mathrm{AB} \text { is at the same height as } \\
\text { the IUT, with the IUT nominally at } 0^{\circ} \text { azimuth angle when } \\
\text { facing the line AB. }\end{array}$ & $\mathrm{b}$ \\
\hline 4 & $\begin{array}{l}\text { As close as } \\
\text { possible, less } \\
\text { than } 3 \mathrm{~m}\end{array}$ & $90^{\circ}$ & $\begin{array}{l}\text { The center of the vertical length } \mathrm{AB} \text { is at the same height as } \\
\text { the IUT, with the IUT nominally at } 90^{\circ} \text { azimuth angle when } \\
\text { facing the line } \mathrm{AB} \text {. }\end{array}$ & $\mathrm{b}$ \\
\hline 5 & $\begin{array}{l}\text { As close as } \\
\text { possible, less } \\
\text { than } 3 \mathrm{~m}\end{array}$ & $0^{\circ}$ & $\begin{array}{l}\text { The center of the left diagonal length } \mathrm{AB} \text { is at the same } \\
\text { height as the IUT, with the IUT nominally at } 0^{\circ} \text { azimuth } \\
\text { angle when facing the center of the line } \mathrm{AB} \text {. The line } \mathrm{AB} \\
\text { makes an angle of } 45^{\circ} \text { with the horizontal. }\end{array}$ & $\mathrm{c}$ \\
\hline 6 & $\begin{array}{l}\text { As close as } \\
\text { possible, less } \\
\text { than } 3 \mathrm{~m}\end{array}$ & $90^{\circ}$ & $\begin{array}{l}\text { The center of the left diagonal length } \mathrm{AB} \text { is at the same } \\
\text { height as the IUT, with the IUT nominally at } 90^{\circ} \text { azimuth } \\
\text { angle when facing the center of the line AB. The line AB } \\
\text { makes an angle of } 45^{\circ} \text { with the horizontal. }\end{array}$ & $\mathrm{c}$ \\
\hline 7 & $\begin{array}{l}\text { As close as } \\
\text { possible, less } \\
\text { than } 3 \mathrm{~m}\end{array}$ & $0^{\circ}$ & $\begin{array}{l}\text { The center of the right diagonal length } \mathrm{AB} \text { is at the same } \\
\text { height as the IUT, with the IUT nominally at } 0^{\circ} \text { azimuth } \\
\text { angle when facing the center of the line AB. The line AB } \\
\text { makes an angle of } 45^{\circ} \text { with the horizontal. }\end{array}$ & $\mathrm{d}$ \\
\hline 8 & $\begin{array}{l}\text { As close as } \\
\text { possible, less } \\
\text { than } 3 \mathrm{~m}\end{array}$ & $90^{\circ}$ & $\begin{array}{l}\text { The center of the right diagonal length } \mathrm{AB} \text { is at the same } \\
\text { height as the IUT, with the IUT nominally at } 90^{\circ} \text { azimuth } \\
\text { angle when facing the center of the line AB. The line } \mathrm{AB} \\
\text { makes an angle of } 45^{\circ} \text { with the horizontal. }\end{array}$ & $\mathrm{d}$ \\
\hline 9 & $\begin{array}{l}\text { As close as } \\
\text { possible, less } \\
\text { than } 3 \mathrm{~m}\end{array}$ & $0^{\circ}$ & $\begin{array}{l}\text { Horizontal length } \mathrm{AB} \text { is raised to a height } l / 2 \text { above the } \\
\text { IUT, with the IUT nominally at } 0^{\circ} \text { azimuth angle when } \\
\text { facing the center of the line } \mathrm{AB} \text {. }\end{array}$ & $\mathrm{e}$ \\
\hline 10 & $\begin{array}{l}\text { As close as } \\
\text { possible, less } \\
\text { than } 3 \mathrm{~m}\end{array}$ & $90^{\circ}$ & $\begin{array}{l}\text { Horizontal length } \mathrm{AB} \text { is raised to a height } l / 2 \text { above the } \\
\text { IUT, with the IUT nominally at } 90^{\circ} \text { azimuth angle when } \\
\text { facing the center of the line } \mathrm{AB} \text {. }\end{array}$ & $\mathrm{e}$ \\
\hline
\end{tabular}




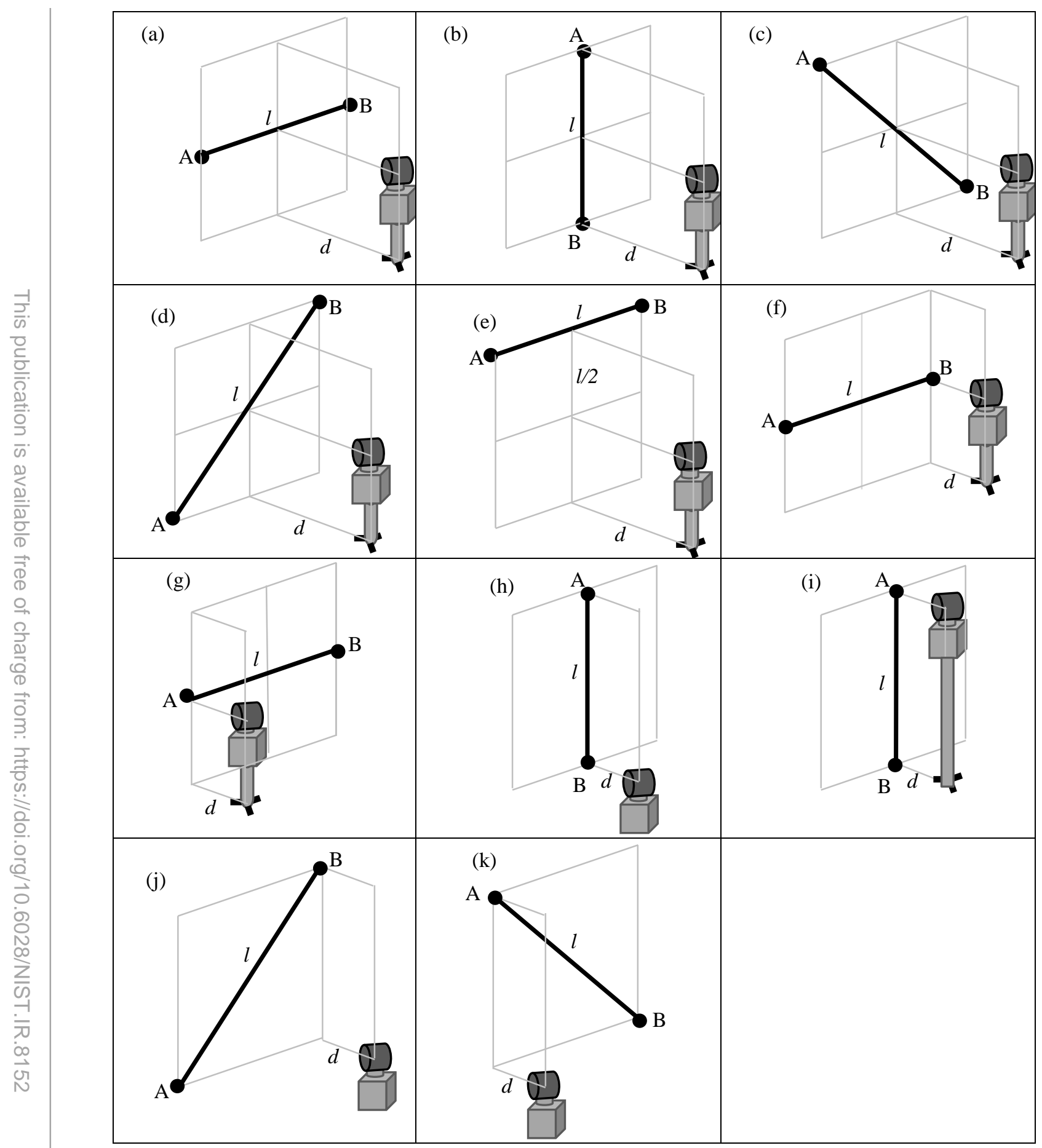

Fig. A2 Near symmetric, near asymmetric, and far symmetric test positions 
Table A3 Near asymmetric measurement positions (see Fig A2), reference length $A B$ is $1.5 \mathrm{~m}$ to $3 \mathrm{~m}$ long

\begin{tabular}{|c|c|c|c|c|}
\hline $\begin{array}{l}\text { Position } \\
\text { number }\end{array}$ & $\begin{array}{l}\text { Distance } d \\
\text { from IUT } \\
\text { (meters) }\end{array}$ & $\begin{array}{l}\text { Azimuth } \\
\text { angle } \\
\text { (degrees) }\end{array}$ & Description & $\begin{array}{l}\text { Sub- } \\
\text { figure }\end{array}$ \\
\hline 11 & $\begin{array}{l}\text { As close as } \\
\text { possible, } \\
\text { not more } \\
\text { than } 3 \mathrm{~m}\end{array}$ & $0^{\circ}$ & $\begin{array}{l}\text { Horizontal length } \mathrm{AB} \text { is placed at the same height as the } \\
\text { IUT with one end directly in front of the IUT (sphere B in } \\
\text { Fig. 2(f)), with the IUT nominally at } 0^{\circ} \text { azimuth angle } \\
\text { when facing that sphere. }\end{array}$ & $\mathrm{f}$ \\
\hline 12 & $\begin{array}{l}\text { As close as } \\
\text { possible, } \\
\text { not more } \\
\text { than } 3 \mathrm{~m}\end{array}$ & $90^{\circ}$ & $\begin{array}{l}\text { Horizontal length AB is placed at the same height as the } \\
\text { IUT with one end directly in front of the IUT (sphere B in } \\
\text { Fig. 2(f)), with the IUT nominally at } 90^{\circ} \text { azimuth angle } \\
\text { when facing that sphere. }\end{array}$ & $\mathrm{f}$ \\
\hline 13 & $\begin{array}{l}\text { As close as } \\
\text { possible, } \\
\text { not more } \\
\text { than } 3 \mathrm{~m}\end{array}$ & $0^{\circ}$ & $\begin{array}{l}\text { This is the mirror position of test position } 11 \text {. Horizontal } \\
\text { length AB is placed at the same height as the IUT with the } \\
\text { other end directly in front of the IUT (sphere A in Fig. } \\
2(\mathrm{~g}) \text { ), with the IUT nominally at } 0^{\circ} \text { azimuth angle when } \\
\text { facing that sphere. }\end{array}$ & $\mathrm{g}$ \\
\hline 14 & $\begin{array}{l}\text { As close as } \\
\text { possible, } \\
\text { not more } \\
\text { than } 3 \mathrm{~m}\end{array}$ & $90^{\circ}$ & $\begin{array}{l}\text { This is the mirror position of test position } 12 \text {. Horizontal } \\
\text { length AB is placed at the same height as the IUT with the } \\
\text { other end directly in front of the IUT (sphere A in Fig. } \\
2(\mathrm{~g}) \text { ), with the IUT nominally at } 90^{\circ} \text { azimuth angle when } \\
\text { facing that sphere. }\end{array}$ & $\mathrm{g}$ \\
\hline 15 & $\begin{array}{l}\text { As close as } \\
\text { possible, } \\
\text { not more } \\
\text { than } 3 \mathrm{~m}\end{array}$ & $0^{\circ}$ & $\begin{array}{l}\text { Vertical length AB is placed with one end directly in front } \\
\text { of the IUT (sphere B in Fig. } 2(\mathrm{~h}) \text { ), with the IUT nominally } \\
\text { at } 0^{\circ} \text { azimuth angle when facing that sphere. }\end{array}$ & $\mathrm{h}$ \\
\hline 16 & $\begin{array}{l}\text { As close as } \\
\text { possible, } \\
\text { not more } \\
\text { than } 3 \mathrm{~m}\end{array}$ & $90^{\circ}$ & $\begin{array}{l}\text { Vertical length AB is placed with one end directly in front } \\
\text { of the IUT (sphere B in Fig. } 2(\mathrm{~h}) \text { ), with the IUT nominally } \\
\text { at } 90^{\circ} \text { azimuth angle when facing that sphere. }\end{array}$ & $\mathrm{h}$ \\
\hline 17 & $\begin{array}{l}\text { As close as } \\
\text { possible, } \\
\text { not more } \\
\text { than } 3 \mathrm{~m}\end{array}$ & $0^{\circ}$ & $\begin{array}{l}\text { This is the mirror position of test position } 15 \text {. Vertical } \\
\text { length AB is placed with the other end directly in front of } \\
\text { the IUT (sphere A in Fig. 2(i)), with the IUT nominally at } \\
0^{\circ} \text { azimuth angle when facing that sphere. }\end{array}$ & $\mathrm{i}$ \\
\hline 18 & $\begin{array}{l}\text { As close as } \\
\text { possible, } \\
\text { not more } \\
\text { than } 3 \mathrm{~m}\end{array}$ & $90^{\circ}$ & $\begin{array}{l}\text { This is the mirror position of test position } 16 \text {. Vertical } \\
\text { length AB is placed with the other end directly in front of } \\
\text { the IUT (sphere A in Fig. 2(i)), with the IUT nominally at } \\
90^{\circ} \text { azimuth angle when facing that sphere. }\end{array}$ & $\mathrm{i}$ \\
\hline 19 & $\begin{array}{l}\text { As close as } \\
\text { possible, } \\
\text { not more } \\
\text { than } 3 \mathrm{~m}\end{array}$ & $0^{\circ}$ & $\begin{array}{l}\text { Asymmetric right diagonal length is placed so that one end } \\
\text { (sphere A in Fig. } 2(\mathrm{j}) \text { ) is at the same height as the IUT and } \\
\text { the other end is directly in front of the IUT but at a raised } \\
\text { position (sphere B in Fig. } 2(\mathrm{j}) \text { ) so that the line AB makes } \\
\text { an angle of } 45^{\circ} \text { with respect to the horizontal. The IUT is } \\
\text { nominally at } 0^{\circ} \text { azimuth angle when facing the sphere } \\
\text { directly in front of it. }\end{array}$ & $\mathrm{j}$ \\
\hline 20 & $\begin{array}{l}\text { As close as } \\
\text { possible, } \\
\text { not more } \\
\text { than } 3 \mathrm{~m}\end{array}$ & $90^{\circ}$ & $\begin{array}{l}\text { Asymmetric right diagonal length is placed so that one end } \\
\text { (sphere A in Fig. } 2(\mathrm{j}) \text { ) is at the same height as the IUT and } \\
\text { the other end (sphere B in Fig. 2(j)) is directly in front of } \\
\text { the IUT but at a raised position so that the line AB makes } \\
\text { an angle of } 45^{\circ} \text { with respect to the horizontal. The IUT is } \\
\text { nominally at } 90^{\circ} \text { azimuth angle when facing the sphere } \\
\text { directly in front of it. }\end{array}$ & $\mathrm{j}$ \\
\hline
\end{tabular}


Table A3 (continued) Near asymmetric measurement positions (see Fig A2), reference length $A B$ is $1.5 \mathrm{~m}$ to $3 \mathrm{~m}$ long

\begin{tabular}{|c|c|c|l|c|}
\hline 21 & $\begin{array}{c}\text { As close as } \\
\text { possible, } \\
\text { not more } \\
\text { than } 3 \mathrm{~m}\end{array}$ & $0^{\circ}$ & $\begin{array}{l}\text { This is the mirror position of test position 19. Asymmetric } \\
\text { left diagonal length is placed so that one end (sphere B in } \\
\text { Fig. 2(k)) is at the same height as the IUT and the other end } \\
\text { is directly in front of the IUT but at a raised position } \\
\text { (sphere A in Fig. 2(k)) so that the line AB makes an angle } \\
\text { of } 45^{\circ} \text { with respect to the horizontal. The IUT is nominally } \\
\text { at } 0^{\circ} \text { azimuth angle when facing the sphere directly in front } \\
\text { of it. }\end{array}$ & $\mathrm{k}$ \\
\hline 22 & $\begin{array}{l}\text { As close as } \\
\text { possible, } \\
\text { not more } \\
\text { than } 3 \mathrm{~m}\end{array}$ & $90^{\circ}$ & $\begin{array}{l}\text { This is the mirror position of test position } 20 \text {. Asymmetric } \\
\text { left diagonal length is placed so that one end (sphere B in } \\
\text { Fig. 2(k)) is at the same height as the IUT and the other end } \\
\text { (sphere B in Fig. 2(k)) is directly in front of the IUT but at a } \\
\text { raised position so that the line AB makes an angle of } 45^{\circ} \\
\text { with respect to the horizontal. The IUT is nominally at } 90^{\circ} \\
\text { azimuth angle when facing the sphere directly in front of it. }\end{array}$ & $\mathrm{k}$ \\
\hline
\end{tabular}

Table A4 Far symmetric measurement positions (see Fig A2), reference length AB is $3 \mathrm{~m}$ to $6 \mathrm{~m}$ long for test \#s 23 through 26 and $6 \mathrm{~m}$ to $8 \mathrm{~m}$ long for test \#s 27 through 29

\begin{tabular}{|c|c|c|l|c|}
\hline $\begin{array}{c}\text { Position } \\
\text { number }\end{array}$ & $\begin{array}{c}\text { Distance } d \\
\text { from IUT } \\
\text { (meters) }\end{array}$ & $\begin{array}{c}\text { Azimuth } \\
\text { angle } \\
\text { (degrees) }\end{array}$ & $\begin{array}{c}\text { Sub- } \\
\text { figure }\end{array}$ & Description \\
\hline 23 & $6 \mathrm{~m}$ to $8 \mathrm{~m}$ & $0^{\circ}$ & $\begin{array}{l}\text { The center of the left diagonal length AB is at the same } \\
\text { height as the IUT, with the IUT nominally at } 0^{\circ} \text { azimuth } \\
\text { angle when facing the center of the line AB. The line AB } \\
\text { makes an angle of } 45^{\circ} \text { with the horizontal. }\end{array}$ & $\mathrm{c}$ \\
\hline 24 & $6 \mathrm{~m}$ to $8 \mathrm{~m}$ & $90^{\circ}$ & $\begin{array}{l}\text { The center of the left diagonal length AB is at the same } \\
\text { height as the IUT, with the IUT nominally at } 90^{\circ} \text { azimuth } \\
\text { angle when facing the center of the line AB. The line AB } \\
\text { makes an angle of } 45^{\circ} \text { with the horizontal. }\end{array}$ & $\mathrm{c}$ \\
\hline 25 & $6 \mathrm{~m}$ to $8 \mathrm{~m}$ & $0^{\circ}$ & $\begin{array}{l}\text { The center of the right diagonal length AB is at the same } \\
\text { height as the IUT, with the IUT nominally at } 0^{\circ} \text { azimuth } \\
\text { angle when facing the center of the line AB. The line AB } \\
\text { makes an angle of } 45^{\circ} \text { with the horizontal. }\end{array}$ & $\mathrm{d}$ \\
\hline 26 & $6 \mathrm{~m}$ to $8 \mathrm{~m}$ & $90^{\circ}$ & $\begin{array}{l}\text { The center of the right diagonal length AB is at the same } \\
\text { height as the IUT, with the IUT nominally at } 90^{\circ} \text { azimuth } \\
\text { angle when facing the center of the line AB. The line AB } \\
\text { makes an angle of } 45^{\circ} \text { with the horizontal. }\end{array}$ & $\mathrm{d}$ \\
\hline 27 & $6 \mathrm{~m}$ to $8 \mathrm{~m}$ & $0^{\circ}$ & $\begin{array}{l}\text { Horizontal length AB is placed at the same height as the } \\
\text { IUT, with the IUT nominally at } 0^{\circ} \text { azimuth angle when } \\
\text { facing the center of the line AB. }\end{array}$ & $\mathrm{a}$ \\
\hline 28 & $6 \mathrm{~m}$ to $8 \mathrm{~m}$ & $30^{\circ}$ & $\begin{array}{l}\text { Horizontal length AB is placed at the same height as the } \\
\text { IUT, with the IUT nominally at } 30^{\circ} \text { azimuth angle when } \\
\text { facing the center of the line AB. }\end{array}$ & $\mathrm{a}$ \\
\hline $6 \mathrm{~m}$ to $8 \mathrm{~m}$ & $60^{\circ}$ & $\begin{array}{l}\text { Horizontal length AB is placed at the same height as the } \\
\text { IUT, with the IUT nominally at } 60^{\circ} \text { azimuth angle when } \\
\text { facing the center of the line AB. }\end{array}$ & $\mathrm{a}$ \\
\hline
\end{tabular}




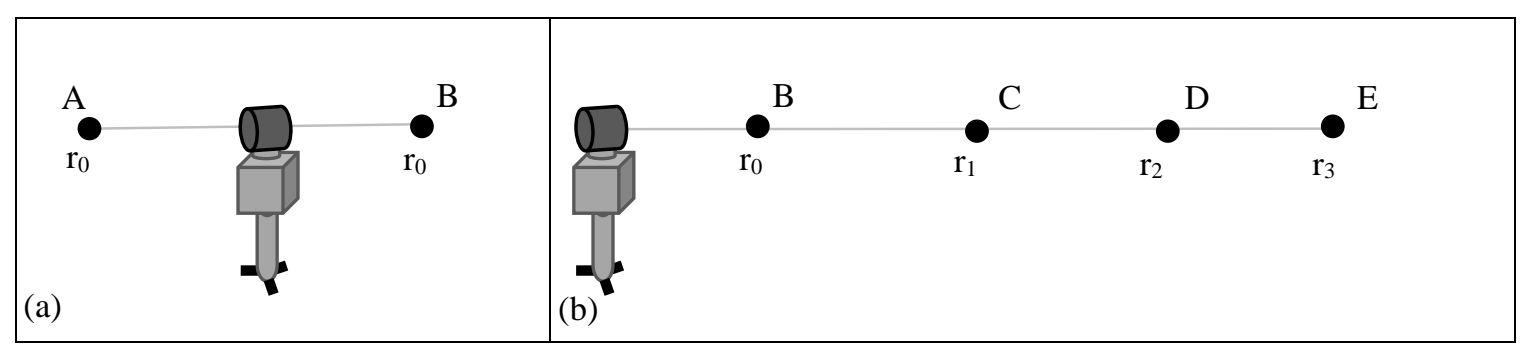

Fig. A3 Ranging direction tests (a) inside test, (b) relative range tests

Table A5 Ranging direction test positions (see Fig. A3)

\begin{tabular}{|c|l|}
\hline $\begin{array}{c}\text { Position } \\
\text { number }\end{array}$ & $\begin{array}{l}\text { Description } \\
\text { Inside test: The two spheres are placed so they are collinear with the IUT, on diametrically } \\
\text { opposite sides of the IUT, and equidistant from the IUT. The spheres are each placed at a } \\
\text { distance } \mathrm{r}_{0} \text { which is at the near position specified by the manufacturer. If the manufacturer does } \\
\text { not specify the near position, the user is free to choose any value for } \mathrm{r}_{0} .\end{array}$ \\
\hline 31 & $\begin{array}{l}\text { Relative range 1: The IUT is placed so that it is collinear with the two spheres B and C. Sphere } \\
\text { B is placed at a distance } \mathrm{r}_{0} \text { which is as close as possible to the instrument as specified by the } \\
\text { manufacturer. The position of sphere C is determined by the user and not to exceed } \\
\text { manufacturer specified maximum range. }\end{array}$ \\
\hline 32 & $\begin{array}{l}\text { Relative range 2: The IUT is placed so that it is collinear with the two spheres B and D. Sphere } \\
\text { B is placed at a distance } \mathrm{r}_{0} \text { which is as close as possible to the instrument as specified by the } \\
\text { manufacturer. The position of sphere D is determined by the user and not to exceed } \\
\text { manufacturer specified maximum range. }\end{array}$ \\
\hline 33 & $\begin{array}{l}\text { Relative range 3: The IUT is placed so that it is collinear with the two spheres B and E. Sphere } \\
\text { B is placed at a distance } \mathrm{r}_{0} \text { which is as close as possible to the instrument as specified by the } \\
\text { manufacturer. The position of sphere } \mathrm{E} \text { is determined by the user and not to exceed } \\
\text { manufacturer specified maximum range. }\end{array}$ \\
\hline
\end{tabular}

Table A6 User defined positions

\begin{tabular}{|c|l|}
\hline $\begin{array}{c}\text { Position } \\
\text { number }\end{array}$ & \multicolumn{1}{c|}{ Description } \\
\hline 34 & $\begin{array}{l}\text { The user is allowed to propose and realize two positions of the reference length anywhere in the } \\
\text { working volume. }\end{array}$ \\
\hline 35 & \\
\hline
\end{tabular}

